\title{
The webbed emergence of fuzzy sets and computer science education from electrical engineering
}

\author{
Rudolf Seising $^{1}$ Marco Elio Tabacchi ${ }^{2}$ \\ ${ }^{1}$ European Center for Soft Computing, Mieres, Asturias (Spain) \\ ${ }^{2}$ DMI Università degli Studi di Palermo and Istituto Nazionale di Ricerche Demopolis (Italy)
}

\begin{abstract}
Historically, Computer science emerged from electrical engineering and from mathematics in the 1960s. From the content of some unpublished documents and also some rather less-well-known papers by Lotfi A. Zadeh it is argued that the emergences of Computer science and Fuzzy Set Theory have been interlinked. Zadeh's task as Chair of the Electrical Engineering Department in Berkeley in the 1960s, his activities in Education of Engineering and his creation of the theory of Fuzzy sets generated his view on the scientific discipline of Computer science as a fuzzy set. This view could establish a new approach to history and philosophy of science.
\end{abstract}

Keywords: Electrical engineering, Fuzzy sets

\section{Introduction}

Science is the general analysis of nature and that is what in ancient times was called natural philosophy. Later on, natural philosophy differentiated into the disciplines of physics (ancient Greek: pv́бıs (physis) "nature") (including astronomy), chemistry, biology and some parts of mathematics. However, there are no strict boundaries between these disciplines and there are overlaps: e.g., biophysics, quantum chemistry etc.

Furthermore today the main branches of physics are much more determined and differentiated e.g., as (Classical) Mechanics, Electromagnetism, Thermodynamics and Statistical mechanics, Relativity theory and Quantum mechanics. However, again we must notice that we cannot sharply separate these elaborated parts of physics from each other. Sometimes, they have concepts in common, e.g., particles, mass points, waves, or they use the same rules and methods, some theories are specialization of more general theories, e.g., Hook's mechanics and Newton's mechanics etc.

In addition, during the $19^{\text {th }}$ century, scientist and engineers established relationships between physics and engineering. Before that time, electricity was considered as part of physics but then, e.g., in 1882, the first chair of Electrical engineering (EE) was founded at the University of Technology (TU) in Darmstadt (Germany) and in the same year the MIT in Boston, USA, offered he first option of EE within a physics department. One year later TU Darmstadt and also Cornell University introduced the world's first courses of study in EE and in 1885 the University College London founded the first chair of electrical engineering in the UK. One year later the University of Missouri established the first department of EE in the USA.
In the present contribution our aim is to show that we are dealing with fuzzy concepts in the area of science and technology. The example employed in this paper is the scientific discipline of computer science (CS) that emerged from Electrical engineering (EE) in the 1960s. In section II we will sketch some aspects of that historical episode from the viewpoint of the electrical engineer Lotfi A. Zadeh who was on one hand a decisive protagonist of this development at the University of California, Berkeley and who founded on the other hand the theory of Fuzzy Sets (FS) during that period. From the content in non-published or not well known documents, found by one of the authors in Zadeh's private archives in his office and at his home follows the claim that the two developments in science, the birth of CS and FS, resp. have been interlinked, viz.:

- The theory of FS emerged from scientific studies in Circuit theory, Network theory, System theory, and Information theory as parts of EE, as well as from mathematical theories and logic, after computers entered the field of technology.

- We can treat the stemming of CS from EE and other scientific theories and methodologies as a fuzzy relationship because the subjects of CS - some of them are also subjects of EE or mathematics or logic etc. and some of them newly created - became part of the new scientific discipline CS only to some degree, as such that CS can be considered itself as a fuzzy set!

Section III deals with this fuzziness of CS in the 1960s. In Section IV we give a conclusion of this historical research and in Section $\mathrm{V}$ a short outlook considers the fuzziness of scientific disciplines in general.

\section{Electrical engineering and the computer era}

Computers have been the most famous technical product of Second World War research - along with the atomic bomb. Computers became popular as "electronic brains" or "thinking machines". Even if the "era of computers" was already started by the analogue MIT Differential Analyzer of Vannevar Bush (1890-1974), the technological development of digital computers was an eminent push with ENIAC (Electronic Numerical Integrator and Computer) and EDVAC (Electronic Discrete Variable Computer), both designed by John Presper Eckert (1919-1995) and John William Mauchly (1907-1980). 


\subsection{Computers - a new field in electrical engineer- ing}

As early as 1950 the British mathematician Alan Mathison Turing (1912-1954) asked in his famous Mind-article "Computing Machinery and Intelligence" [1] "Can machines think?". Instead of an answer he proposed a variation of the then well-known imitation game, lately renamed the "Turing test", that highlighted a philosophical interest in the problem of deciding whether a computer or a program could think like a human being or not. In those days Lotfi Aliasker Zadeh (born 1921) was a young electrical engineer with deep interest in the new-by-then computing machines. He wrote a paper "Thinking Machines. A New Field in Electrical Engineering", which appeared in The Columbia Engineering Quarterly in the same year [2]. Here, Zadeh put for discussion questions "How will «electronic brains» or «thinking machines» affect our way of living?" and "What is the role played by electrical engineers in the design of these devices?" ([2], p. 12.) He was looking for "the principles and organization of machines which behave like a human brain. Such machines were then variously referred to as "thinking machines", "electronic brains", "thinking robots", and other similar names.

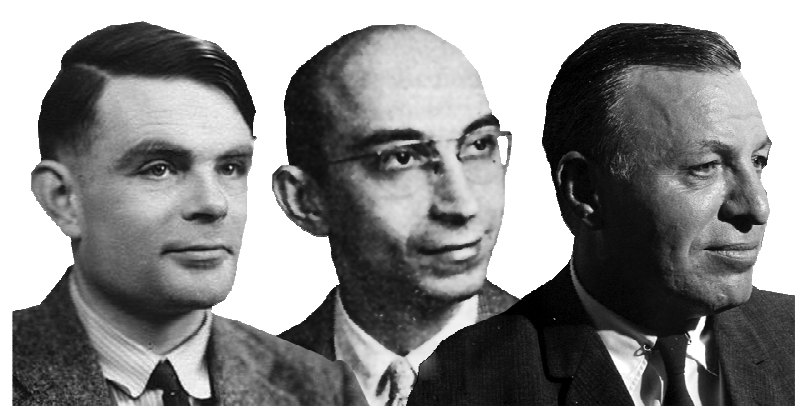

Figure 1: Turing, Zadeh, Ragazzini.

The fundamental principles of thinking machines, Zadeh stressed, were developed by mathematicians, but the physical realization, the construction of the thinking machines, was the task of electrical engineers, who design and build the memory chips, processors, "computors", decision makers, etc. Until now, if electrical engineers had come into contact at all with such heretofore far-removed subjects as Boolean algebra, polyvalent logic, etc., it was through so far off when it would be just as important for post-graduate electrical engineers to take classes in mathematical logic as classes on complex variables: "Time marches on." ([2], p. 31).

\subsection{From circuits to systems}

In 1954 Zadeh published, again in the Columbia Engineering Quarterly, the article "System Theory" [3] where he characterized systems as a "black boxes" with inputs and outputs, and asserts that if these inputs and outputs are describable as time dependent functions then the dynamic behaviour of the system can be studied mathematically, and as such the input-output- relationship of the system states that the output is just a function of the input.

Zadeh believed that it was only a matter of time before system theory would attain acceptance. It turns out that he was right: Eight years later, he wrote the article "From Circuit Theory to System Theory" [4] for the anniversary edition of the Proceedings of the IRE appeared in May 1962 to mark the 50th year of the Institute of Radio Engineers (IRE). He could describe problems and applications of system theory and its relations to network theory, control theory, and information theory: "It has been brought about, largely within the past two decades, by the great progress in our understanding of the behavior of both inanimate and animate systemsprogress which resulted on the one hand from a vast expansion in the scientific and technological activities directed toward the development of highly complex systems for such purposes as automatic control, pattern recognition, data-processing, communication, and machine computation, and, on the other hand, by attempts at quantitative analyses of the extremely complex animate and man-machine systems which are encountered in biology, neurophysiology, econometrics, operations research and other fields" ([4], p. 856f.).

After 1959, when Zadeh became a professor of electrical engineering at the University of California, Berkeley, he published papers on system theory and two well-known books with colleagues at his EE department $[5,6]$.

\subsection{Electrical filtering}

Already during his time in New York, when he joined the faculty of Columbia University as an instructor and since 1950 he was appointed assistant professor, he was excited by Cybernetics [7] of Norbert Wiener (18941964) and he was interested in the theory of ideal and optimal filtering. Together with his supervisor John Ralph Ragazzini (1912-1988) he published in 1950 "An Extension of Wiener's Theory of Prediction" [8], an important milestone in the development of network synthesis.

The mathematical techniques of the theory of prediction and filtering have been commonly employed in mathematical physics, particularly in quantum mechanics, e.g., multi-dimensional Euclidean spaces and Hilbert space representation. In his many papers on prediction and filtering, linear and nonlinear systems, timevariying networks, etc. in the first 1950s, Zadeh used the mathematical calculus of functionals and operators. The analogy between projection in a function space and filtration with an ideal filter led Zadeh in the early 1950s to a functional symbolism of filters [9]. Following Wiener's work and continuing his collaboration with his supervisor Ragazzini Zadeh used the concept of optimal filters instead of ideal filters. Ideal filters are defined as filters which achieve a perfect separation of signal and noise, but in reality no such filter exists. He knew from experience that characteristics of electrical filters don't show an exact step at the limiting frequency but smooth functions. Zadeh discussed optimal filters that give the "best approximation" of a signal and 
he noticed that "best approximations" depend on reasonable criteria. In that time he formulated these criteria in statistical terms, but during the course of his work on optimum filters in the mid-50s he turned away from statistical methods, and recognized that a more promising approach was that of finding an optimum filter relative to a distance to be minimized in the function space of the signals.

At the time Zadeh was working constructively to bridge the gap between theory and practice; he was however forced to recognize that these attempts would not be successful: "As a mathematically oriented system theorist, I had been conditioned to believe that the analytical tools based on set theory and two-valued logic are all that is needed to build a framework for a precise, rigorous and effective body of techniques for the analysis of almost any kind of man-made or natural system. Then, in 1961-1963, in the course of writing a book on system theory (with C. A. Desoer), I began to feel that complex systems cannot be dealt with effectively by the use of conventional approaches largely because the description languages based on classical mathematics are not sufficiently expressive to serve as a means of characterization of input-output relations in an environment of imprecision, uncertainty and incompleteness of information." [10]

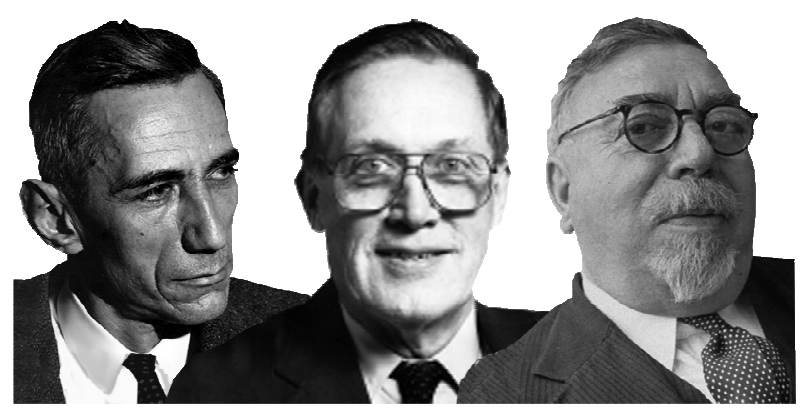

Figure 2:Shannon, Desoer, Wiener.

There were two ways of overcoming this situation. In order to describe the actual systems appropriately, he could try to increase the mathematical precision even further, but this course of action led nowhere. The other way presented itself in the year 1964, when Zadeh discovered how he could describe real systems as they appeared to people. "I'm always sort of gravitated toward something that would be closer to the real world" [11]. The "closer to the real world" thing was the Theory of Fuzzy Sets (FS)!

\subsection{Mathematics and logics}

Zadeh's resignation with usual mathematics would soon lead to capitulation. He was nearing a crossroads. Herbert E. Robbins (1915-2001) (Figure 3, right) was the chairman of Columbia University's department of mathematical statistics at the time. He was a good friend of Zadeh as well as of Deane Montgomery (1909-2002) (Figure 3, left), a member of the Institute for Advanced Study (IAS) in Princeton. Robbins and Montgomery campaigned for the approval of the IAS guest residency for which Zadeh had applied, even though it was rare for requests by scientists who were neither mathematicians nor theoretical physicists or historians to receive a positive response [12]. Zadeh initially took a half-year sabbatical from Columbia University in 1956 . He wanted to learn more about logic, an interest he had cultivated since 1950, when he predicted that logic, and particularly multi-valued logic, would become increasingly more important to the problems of electrical engineering in the future. [19]

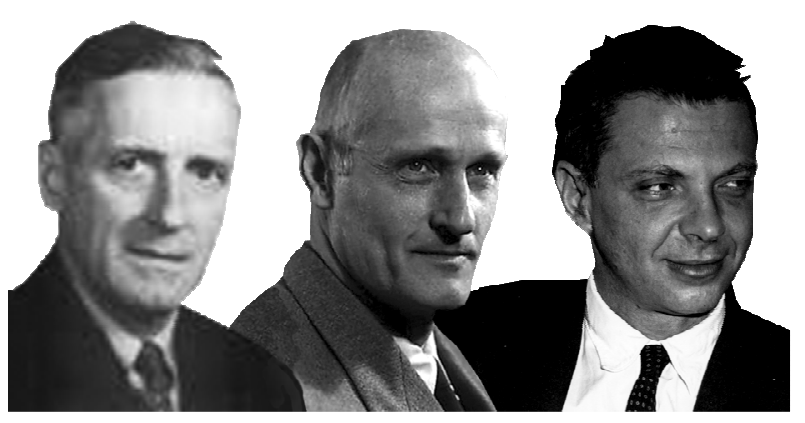

Figure 3: Montgomery, Kleene, Robbins.

The Princeton ambiance quickly inspired Zadeh who remarked it being the "Mecca for mathematicians" [12]. He attended lectures by Stephen Kleene (1909-1994) (Figure 3, mid), who had also continued developing the multi-valued logic devised by the Polish school of logic. Kleene became Zadeh's friend and mentor at Princeton: "Steven Kleene was my teacher in logic. Yes, I learned logic from Steven Kleene!" [10].

This residency had revealed to Zadeh some completely new perspectives of scientific life and work. New ways of thinking had come from the mathematics philosophers in Princeton, and thanks to them he had learned new mathematical methods from statistics, game and decision theory. He also experienced new views of system theory and the newly established automata theory. He had apparently become familiar with Automata Studies, published during this period by Claude Elwood Shannon (1916-2001) and John McCarthy (1927-2011). All of the knowledge, impetus and impressions he found at the IAS would have a lasting effect on Zadeh's future endeavors!

Zadeh found multi-valued logic to be a natural generalization of the conventional logic of just two values into $n$ values, similar to the leap from twodimensionality to $n$-dimensionality in mathematics. [12] He was now also toying with the idea of introducing multi-valued logic into automata theory and implementing it in electric circuits, and once he had returned to Columbia University in New York he assigned two dissertations that dealt with the subjects of multi-valued logic in the design of transistor circuits and with multivalued coding:

- Oscar Lowenschuss wrote the dissertation Multi-Valued Logic and Sequential Machines or Non-Binary Switching Theory the following year [13]. Parts of this paper had been published previously [14]. See also the later publication [15]; 
- Werner Ulrich managed to finish his dissertation Nonbinary Error Correction Codes in 1957 [16].

"That's why I wanted to know about logics!" Zadeh recalled when interview by Seising in the year 2000 [10].

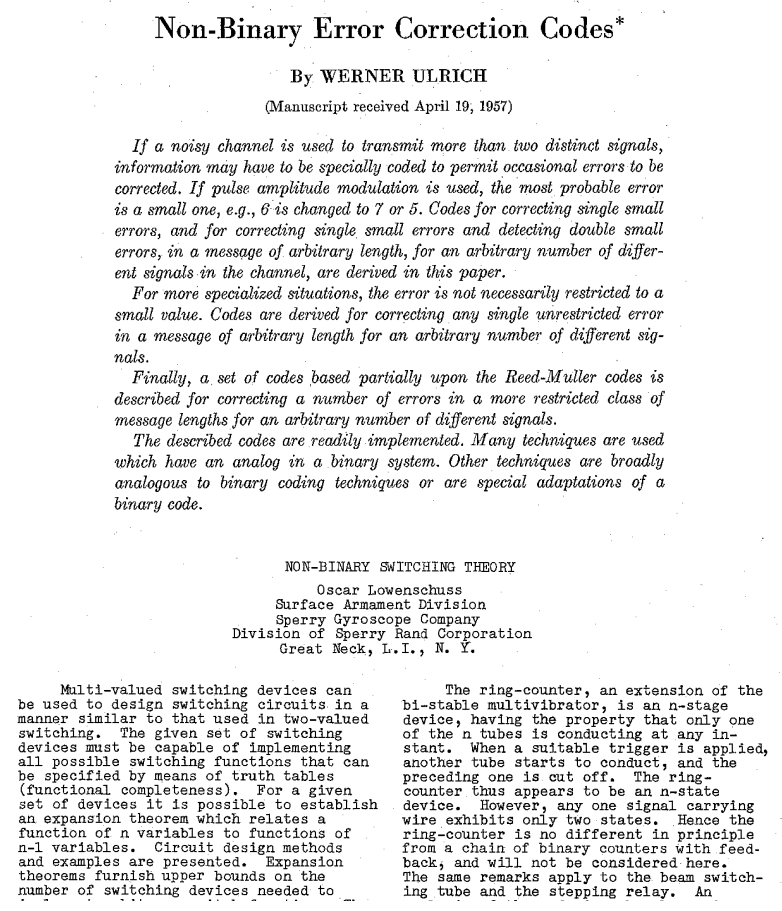

Figure 4: First pages of the $\mathrm{Ph} \mathrm{D}$ dissertation thesis by Ulrich [16] and Lowenschuss [13] in 1957 and 1958

\subsection{Information and communication}

The value to that scientific community which Zadeh recognized in an institute like IAS in Princeton can also be seen in his dedication to establishing a similar institute for his own scientific community. Since the late 1940s he was enthused over Shannon's "Mathematical Theory of Communication" (later called for short Information theory) [13], and when he once again composed an editorial for the IRE Transactions on Information Theory in 1960, it was entitled "Toward an Institute for Research in Communication Science" [17] (Figure 5). He had in the meantime become a professor at Berkeley and he apparently sometimes longed for the freedom he had enjoyed as a guest scientist in Princeton. He called for an Institute for Communication Science to be founded, where scientists could spend a year or two concentrating exclusively on their research without being distracted by teaching and administrative duties, contract negotiations and doctoral advising. This was the only way to guarantee a free choice of research topics and scientifically communicative exchange with no outside pressure!

A number of well-known institutions both in the United States and abroad have these characteristics, but they are embodied perhaps in their purist form in the IAS, which since its inception in 1930 had played a very significant role in the development of mathematics in their country [17]. The IAS, Germany's Max-Planck-
Institutes or the Institute for Automatics and Telemechanics in the Soviet Union did not necessarily have to serve as models for the institute he hoped to establish. Rather it would be designed to meet the specific needs and interests of workers in the fields of information theory, communication theory, system theory, control theory, automata, biological systems, computation, machine translation of languages and related fields. It would be concerned with both theoretical and experimental research in this area [17].

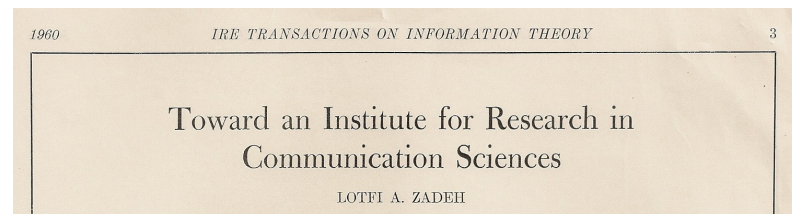

Figure 5: Zadeh's editorial in 1963, [17], excerpt.

After Zadeh had also joined the editorial board of the IRE Transactions on Automatic Control in 1962, he wrote "A Critical View of Our Research in Automatic Control" for the April edition, an article in which he repeated his call for the founding of such an institute. Here he suggested establishing an Institute for Control Science and Engineering, then he added: "(or, more broadly, an Institute for Research in Information Sciences) which would serve as a focal point on the national level for research in control theory and its applications as well as in such related fields as system theory, information and communication theories, circuit theory, machine computation, automata theory, bionics, etc." ([18], p. 74).

The many new impressions, encounters, discussions and insights in Princeton had steered Zadeh's future scientific work in new directions.

\subsection{Fuzzy sets}

As we have seen before, Zadeh had extensively criticized the relationship between mathematics and his own scientific-technical EE discipline. The tool offered by mathematics was not appropriate to the problems that needed to be handled in the engineering sciences. Information and communications technology had led to the construction and design of systems that were so complex that it took much more effort to measure and analyze these systems than had been the case just a few years before. Much more exact methods were now required to identify, classify or characterize such systems or to evaluate and compare them in terms of their performance or adaptivity.

In order to provide a mathematically exact expression of experimental research with real systems, it was necessary to employ meticulous case differentiations, differentiated terminology and definitions that were adapted to the actual circumstances, things for which the language normally used in mathematics could not account. The circumstances observed in reality could no longer simply be described using the available mathematical means.

In the summer of 1964 Zadeh was thinking about pattern recognition problems and grades of membership of 
an object to be an element of a class; almost 50 years later, he returns with the mind to these times as such: "While I was serving as Chair, I continued to do a lot of thinking about basic issues in systems analysis, especially the issue of unsharpness of class boundaries. In July 1964, I was attending a conference in New York and was staying at the home of my parents. They were away. I had a dinner engagement but it had to be canceled. I was alone in the apartment. My thoughts turned to the unsharpness of class boundaries. It was at that point that the simple concept of a fuzzy set occurred to me. It did not take me long to put my thoughts together and write a paper on the subject. This was the genesis of fuzzy set theory." ([19], p. 7). ${ }^{1}$

Zadeh submitted his first article "Fuzzy Sets" to the editors of Information and Control in November 1964 and it appeared in this journal in the following June [20]. He introduced new mathematical entities as classes or sets that "are not classes or sets in the usual sense of these terms, since they do not dichotomize all objects into those that belong to the class and those that do not." He introduced "the concept of a fuzzy set, that is a class in which there may be a continuous infinity of grades of membership, with the grade of membership of an object $x$ in a fuzzy set $A$ represented by a number $f_{A}(x)$ in the interval $[0,1] . "$ [21]

The question was how to generalize various concepts, union of sets, intersection of sets, and so forth. Zadeh defined equality, containment, complementation, intersection and union (Figure 6) relating to fuzzy sets $A, B$ in any universe of discourse $X$ as follows (for all $x$ $\in X)$ :

- $A=B$ if and only if $\mu_{A}(x)=\mu_{B}(x)$,

- $A \subseteq B$ if and only if $\mu_{A}(x) \leq \mu_{B}(x)$,

- $\neg A$ is the complement of $A$, if and only if $\mu \neg_{A}(x)=1-\mu_{A}(x)$,

- $A \cup B$ if and only if $\mu_{A \cup B}(x)=\max \left(\mu_{A}(x)\right.$, $\left.\mu_{B}(x)\right)$,

- $A \cap B$ if and only if $\mu_{A \cap B}(x)=\min \left(\mu_{A}(x)\right.$, $\left.\mu_{B}(x)\right)$.

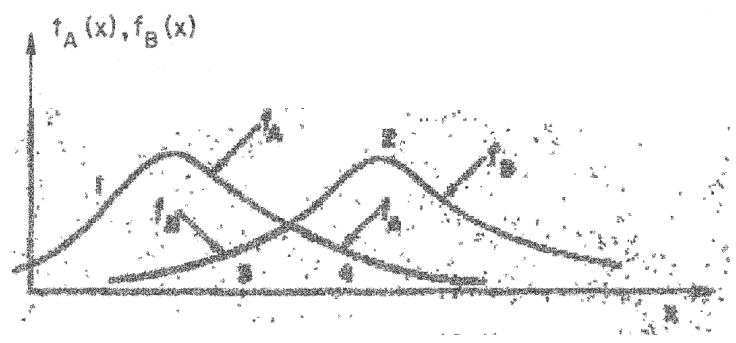

Figure 6: Zadeh's Illustration of fuzzy sets in $\mathrm{R}^{1}$ : "The membership function of the union is comprised of curve segments 1 and 2; that of the intersection is comprised of segments 3 and 4 (heavy lines)." ([21], p. 342).

\footnotetext{
${ }^{1}$ A detailed presentation of the history of the theory of FS is given in the one of the authors' book [20].
}

\subsection{From the department of electrical engineering (EE) to the department of electrical engineer- ing and computer sciences (EECS)}

In one of Seising's interviews Zadeh recalled: "System Theory came grown up but then computers and computers then took over. In other words: the center of attention shifted. ... So, before that, there were some universities that started departments of system sciences, departments of system engineering, something like that, but then they all went down. They all went down because computer science took over." [11]

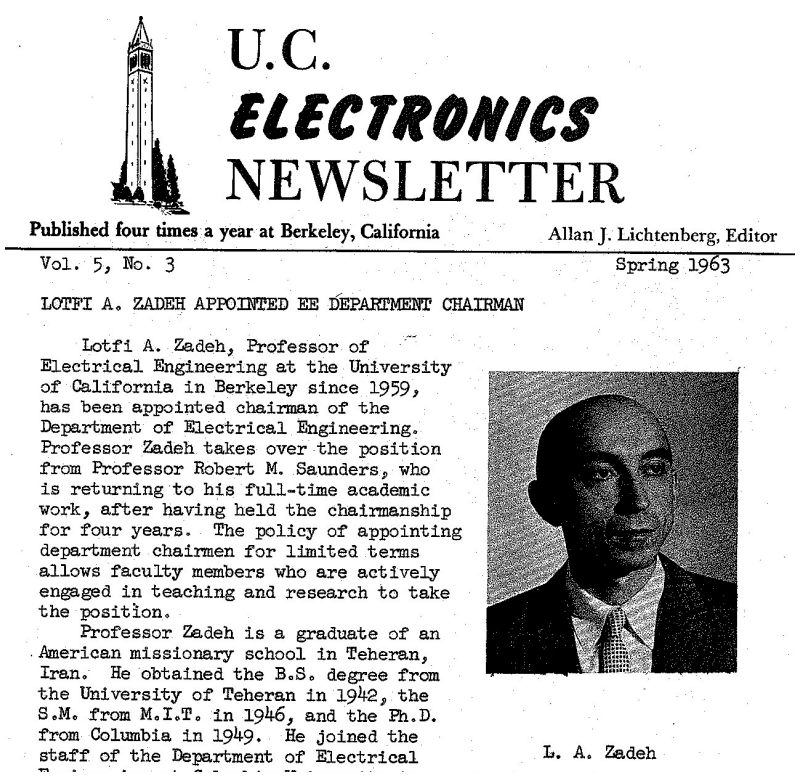

Figure 7: Zadeh became chair in 1963, (excerpt).

When Zadeh become chairman of the department of electrical engineering (EE) at Berkeley in 1963 (Figure 7), he experienced such shifts very intensively, for it was during his five-year tenure in this position that his department was renamed the Department of Electrical Engineering and Computer Science (EECS) [11]. In November 1992 Zadeh was asked to give an after dinner talk on the history of CS at Berkeley. In the manuscript for this talk he wrote: "I joined the EE Department in 1959. At that time, the EE Department was best known for its work in electromagnetism and microwaves. A decision was made to build up the area of circuits, systems and control. Don Pederson, Ernie Kuh and Charles Desoer came from Bell Labs. Eli Jury, Art Bergen and I came from Columbia University. [...] There wasn't much activity in the computer field at that time, but there was was significant. [...] There was a Computer Centre in Cory Hall that was run by the EE Department. The principal and only figures in computer science and engineering in $\mathrm{EE}$ at that time were Paul Morton and Harry Huskey. They can be rightly regarded as the progenitors of Computer science and engineering at Berkeley." [...] When I was appointed as Chairman in 1963, I was not a computer person and I am not a computer user to this day, I regret to say. But I was always a very strong believer in the importance of computers and digital technology. My first action as 
Chairman was to send a memo to the faculty in which I suggested that we assign the highest priority to the development of computer science in EE. But what it was obvious today was not so obvious then. The reaction to my memo was mixed and some influential faculty members objected strongly to my proposal.” [22]

After some initial difficulties, Zadeh was finally successful in changing the name of the department to EECS. In his article "Electrical Engineering at the Crossroads" published in 1965 [23] (Figure 6) he described the problem as such: "The slowness with which many electrical engineering departments have reacted to the rapidly growing demand for computer scientists and engineers, and their unwillingness to make substantive changes in their curricula to meet the need for specialized training in computer sciences and related fields, is generating strong pressures on some campuses to establish separate computer science departments." ([23], p. 30) In the same article he presented the new EE curriculum at Berkeley that "reflects the fact that, today, electrical engineering is no longer an aggregation of a small number of subject areas sharing a large common body of concepts and techniques - as it was in the thirties, forties, ant to a lesser extent, in the fifties. Rather, it is an assemblage of a wide range of subjects, falling into three major areas which have a relatively small common core. [...] If this premise is accepted, then the only logical conclusion is that the student must be provided with a choice of several basic programs, which could permit him to focus his studies in one of the major areas falling within or nearest to his main field of interest." ([23], p. 31)

\section{Electrical Engineering at the Crossroads} L. A. ZADEH, FELLOW, IEEE

Figure 8: Excerpt of Zadeh's article in1965, [23].

At Berkeley three programs (A: Electronics, Fields, and Plasmas; $B$ : Systems, Information, and Control and $C$ : Computer Sciences) and a "General EE program" $D$ were established ([23], p. 31f).

Three years later Zadeh gave a talk on "Education in Computer Science" at Israel's $4^{\text {th }}$ National Conference on Data Processing that took place in the Hebrew University Jerusalem (Figure 8). Initially, he claimed that computer science "as a collection of concepts and techniques which serve to systematize the employment of the means with which modern technology provides us for purposes of stage, representation and processing of information." ([24], p. E157) In the printed version of this talk he affirmed that "Computer science cuts across the boundaries of many established fields. It is glamorous; it draws a large number of students - many of them from other departments; it is hitched to the bandwagon of computers and the information revolution." ([49], p. E158)

In the same paper he discussed some details of "Berkeley's solution" to the CS-problem that bred finally a Department of CS in the College of Letters and Science and a program in CS in the College of Engineering within the Department of EECS. By way of explanation he added: "Essentially, the main premise of
Berkeley's "solution" is that computer science is not a homogeneous and unified field - at least not at this time - and that, in paraphrased words of Professor A. Oettinger of Harvard, «... it has some components which are the purest of mathematics and some that are the dirtiest of engineering.» [25] This split personality of computer science makes it very difficult to create a single academic unit within the university structure where mathematically oriented automata theorists, formal language experts, numerical analysts and logicians could establish a comfortable modus vivendi with nonmathematical oriented hardware designers, systems programmers and computer architects. [...] In essence, the Berkeley "solution" provides a partial answer to the dilemma by dividing computer science not into two non-overlapping parts but into two overlapping parts which differ from one another mainly in degrees of emphasis places on various subject areas." ([29], p. E164f)

\section{EDUCATION IN COMPUTER SCIENCE}

PROF. L.A. ZADEH

DEPRTMENT OF ELECTRICAL ENGINEERING \& COMPUTES SCIENCES, UNIVERSITY OF CALIFORNIA. BERKELEY

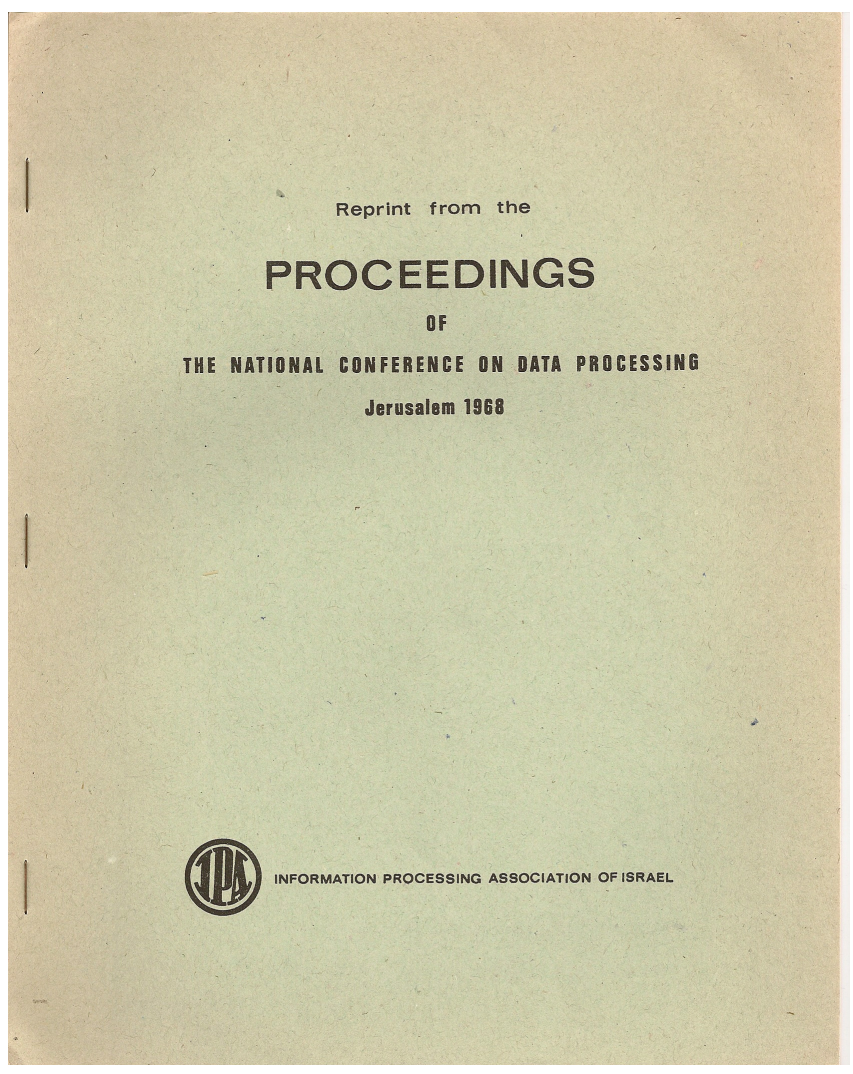

Figure 9: Reprint of Zadeh's paper in1968, [24].

In his article "Computer Science as a Discipline", that appeared in the same month in the Journal of Engineering Education [26] (fig. 10), he also characterized $\mathrm{CS}$ this way. He wrote what was "pointed out in the authoritative reports of the ACM Curriculum Committee on Computer Science [27, 28] computer science is not simply concerned with the design of computing devices, nor is it just the art of numerical calculation. Essentially, computer science is concerned with information 
in much the same way that physics is concerned with energy; it is devoted to the representation, storage, manipulation and presentation of information in an environment permitting automatic information systems." ([26], p. 913)

\section{Computer Science as a Discipline

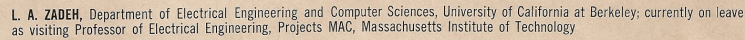

Figure 10: Excerpt of Zadeh's article [26], 1968

Concerning his view that CS "cuts across the boundaries of many established fields" and also that the parts of CS differ from one another "in degrees of emphasis", Zadeh then presented a new idea in the field of CS education: because of the broadness and vagueness of the statement "to convey even a rough idea of the boundaries of computer science and its relation to mathematics, electrical engineering and other neighboring fields", he introduced his idea of fuzzy sets, to employ a new approach: "Specifically, let us regard computer science as a name for a fuzzy set of subjects and attempt to concretize its meaning by associating with various subjects their respective degrees of containment (ranging from 0 to 1 ) in the fuzzy set of computer science. For example, a subject such as «programming languages» which plays a central role in computer science, will have a degree if containment equal to unity. On the other hand, a peripheral subject such as «mathematical logic» will have a degree of containment of, say, 0.6." ([26], p. 913.)

TABLE 1

Containment Table for Computer Science

\begin{tabular}{lc}
\hline \multicolumn{1}{c}{ Subject } & $\begin{array}{c}\text { Degree of } \\
\text { Containment } \\
\text { in Computer } \\
\text { Science }\end{array}$ \\
\hline Programming languages & 1 \\
Computer design and organization & 1 \\
Data structures & 1 \\
Models of computation & 1 \\
Operating systems & 1 \\
Programming systems & 1 \\
Formal languages and grammars & 0.9 \\
Computational linguistics & 0.8 \\
Automata theory & 0.8 \\
Finite-state systems & 0.8 \\
Theory of algorithms & 0.9 \\
Discrete mathematics & 0.8 \\
Mathematical logic & 0.6 \\
Combinatorics and graph theory & 0.8 \\
Dynamic programming & 0.7 \\
Mathematical programming & 0.7 \\
Numerical methods & 0.8 \\
Switching theory & 0.8 \\
Analog and hybrid computers & 0.7 \\
Computer graphics & 0.7 \\
Digital devices and circuits & 0.7 \\
Artificial intelligence and heuristic programming & 0.9 \\
Information retrieval & 0.7 \\
Information theory and coding & 0.6 \\
Pattern recognition and learning systems & 0.6 \\
\hline & \\
\hline & \\
\hline
\end{tabular}

Figure 11: Illustration in Zadeh's article [26], 1968.
Under the heading "Containment Table for Computer Science" (Figure.19) he arranged the most relevant "subjects in question and their degrees of containment in computer science". Zadeh explained: "Clearly, such numerical values of degrees of containment represent merely this writer's subjective assessment, expressed in quantitative terms, of the current consensus regarding the degrees of inclusion of various subjects in computer science." ([26], p. 913.) He also emphasized "that a high degree of containment of a particular subject in computer science does not imply that it cannot have a similar high or even higher grade of containment in some other field. For example «automata theory» has the degree of containment of 0.8 in computer science; it also has the same, or nearly the same, degree of containment in system theory. Also, the subjects listed in the table may have substantial overlaps with one another. This is true, for example, of "Automata theory» and «finite state systems»." ([26], p. 914.)

\section{Outlook}

The historical aspects described in this paper are only hints of the complete history of relationships between Fuzzy Sets, Computer Science, Electrical Engineering and the other branches of science. This work will be continued by generalization of Zadeh's "fuzzy conception" of Computer science to other scientific disciplines. In the hopes of the authors, this should breed to a new concept in philosophy of science.

\section{Acknowledgment}

We would like to thank Lotfi A. Zadeh for his support to this work.

\section{References}

[1] A.M. Turing, Computing Machinery and Intelligence. In: Mind, vol. LIX, 1950, pp. 433-460.

[2] L.A. Zadeh, Thinking machines - a new field in electrical engineering, Columbia Engineering Quarterly, January 1950, pp. 12-13, 30-31.

[3] L.A. Zadeh, System Theory, Columbia Engineering Quarterly, Nov. 1954, pp. 16-19, and 34.

[4] L.A. Zadeh, From Circuit Theory to System Theory, Proceedings of the IRE, vol. 50, 1962, pp. 856865.

[5] L.A. Zadeh, Ch. A. Desoer: Linear System Theory: The State Space Approach. New York, San Francisco, Toronto, London: McGraw-Hill Book Comp., 1963.

[6] L. A. Zadeh, E. Polak, System Theory, Bombay, New Delhi: McGraw-Hill 1969.

[7] N. Wiener: Cybernetics or Control and Communications in the Animal and the Machine, Cambridge, Massachusetts: MIT Press, 1948.

[8] L.A. Zadeh, J.R. Ragazzini: An Extension of Wiener's Theory of Prediction, Journal of Applied Physics, vol 21, 1950, pp. 645-655. 
[9] L.A. Zadeh: Theory of Filtering, Journal of the Society for Industrial and Applied Mathematics, vol. 1, 1953, pp. 35-51.

[10] R. Seising: Interview with L.A. Zadeh on July, 26, 2000, University of California, Berkeley, Soda Hall.

[11] R. Seising: Interview with L.A. Zadeh on June 15, 2001, University of California, Berkeley, Soda Hall.

[12] R. Seising: Interview with L.A. Zadeh on June 16, 2001, University of California, Berkeley, Soda Hall.

[13] O. Lowenschuss: Multi-Valued Logic in Sequential Machines. Ph.D. Thesis. School of Engineering, Columbia University, New York, 1958.

[14] O. Lowenschuss: A Comment on Pattern Redundancy, IRE Transactions on Information Theory, $\mathrm{p}$ 127, December 1958.W.F. Atchison et al.: An Undergraduate Program in Computer SciencePreliminary Recommendations, Communications of the ACM, vol. 8, pp. 543-552, September 1965.

[15] O. Lowenschuss: Restoring Organs in Redundant Automata, Information and Control, vol. 2, pp. 113-136, 1959.W.F. Atchison et al.: Recommendation for Academic Programs in Computer Science, Communications of the ACM, vol. 11, March 1968.

[16] W. Ulrich: Nonbinary Error Correction Codes, Bell Systems Technical Journal, pp. 1341-1142, November 1957.

[17] L.A Zadeh: Toward an Institute for Research in Communication Sciences. IRE Transactions on Information Theory, Editorial, p. 3, March 1960.

[18] L.A. Zadeh: A Critical View of Our Research in Automatic Control, IRE Transactions on Automatic Control, AC-7, No. 3, pp. 74-75, April 1962.
[19] L.A. Zadeh: My Life and Work - a Retrospective View. Applied and Computational Mathematics, vol. 10, Nr. 1, 2011, pp. 4-9.

[20] R. Seising: The Fuzzification of Systems. The Genesis of Fuzzy Set Theory and Its Initial Applications - Developments up to the 1970s, Studies in Fuzziness and Soft Computing Vol. 216, Berlin, New York, [et al.]: Springer 2007.

[21] L.A. Zadeh: Fuzzy Sets, Information and Control, vol. 8, 1965, pp 338-353.

[22] L.A. Zadeh: History of Computer Science at Berkeley, Manuscript from November 1, 1992, Personal Archive of L.A. Zadeh, page 2.

[23] L.A. Zadeh: Electrical Engineering at the Crossroads, IEEE Transactions on Education, Vol. E-8, Nos 2-3, June-September 1965, pp. 30-33.

[24] L.A. Zadeh: Education in Computer Science, Proceedings of the National Conference on Data Processing, Jerusalem, Information Processing Association of Israel, 1968, pp. E157-E167.

[25] A.G. Oettinger: The Harvard-SoftwareComplementarity, Communications of the ACM, vol. 10, October 1967, pp. 604-606.

[26] L.A. Zadeh: Computer Science as a Discipline, Journal of Engineering Education, Vol. 58, No. 8, April 1968, pp. 913-916.

[27] W.F. Atchison et al.: An Undergraduate Program in Computer Science-Preliminary Recommendations, Communications of the ACM, vol. 8, pp. 543-552, September 1965.

[28] W.F. Atchison et al.: Recommendation for Academic Programs in Computer Science, Communications of the ACM, vol. 11, March 1968. 